\title{
Effect of Long-term Service on Microstructure and Mechanical Properties of NiCrMoV Steel Welded Joint
}

\author{
Manjie Fan ${ }^{1 *}$, Peng Wang ${ }^{1}$, and Qixing Sun $^{2}$ \\ ${ }^{1}$ Technology Development Department, Shanghai Electric Power Generation Equipment Co. , Ltd. Shanghai \\ ${ }^{2}$ Department of Mechanical Engineering, Tsinghua University, Beijing, China
}

\begin{abstract}
The influences of prolonged service on microstructure evolution and mechanical properties of $\mathrm{NiCrMoV}$ steel welded joint in an ex-service welded steam turbine rotor were investigated. The welded rotor had been operated for 22 years since 1991. The specimens for the present study were taken from the location where the temperature was as high as $230^{\circ} \mathrm{C}$. The optical microscope $(\mathrm{OM})$ showed that even after long-term service, there were no obvious defects such as creep cavities, cracks found in the microstructure of the whole welded joint after such a long term service. The microstructure was uniform and no obvious grain coarsening was observed. However some black strip-shaped zones were found in base metal and heat affected zone (HAZ). The distribution of hardness across the welded joints showed no anomalies. The results of tensile strength and fracture toughness tests demonstrated that the welded joint still exhibited excellent. Mechanical performance after long-term service, indicating that the welding process of Shanghai Turbine Plant was reliable and stable. With the improvement of forging and welding qualities and improved heat treatment furnaces with more accurately controlled temperature, it is reasonable to assume that the current large low-pressure (LP) welded rotors are definitely safe to operate under similar service conditions for designed life.
\end{abstract}

\section{Introduction}

Steam turbine rotor is the key component in fossil fired power plants and nuclear power plants, and its reliability and stability have a decisive effect on the safety and service life of steam turbine. Welded rotors have become a trend of rotor development in high-capacity steam turbine due to its advantages of compactness and allowance for manufacturing large scaled rotors with many small forgings. The NiCrMoV steels have been used world widely for LP welded rotor manufacturing. Complicated welding thermal cycles lead to heterogeneous microstructures in weld metal, which tends to become an important factor affecting the reliability of the power generation equipment during long-term service under severe working conditions. At present, only a few companies have the ability to manufacture welded rotors.

Metallographic evaluation and mechanical properties tests, such as tensile strength, impact toughness tests, and fracture toughness tests are mainly carried out on welded joints before service, which were only suitable for performance evaluation at early stage of service. Operation at elevated temperatures for long terms may lead to deterioration in mechanical properties due to changes in microstructures, such as grain coarsening, precipitates coarsening and coalition, dislocation annihilation and so on. Several investigations have been carried out on evolution of microstructure and mechanical properties of $\mathrm{CrMo}$ and $\mathrm{CrMoV}$ steels for high-pressure (HP) and intermediate-pressure (IP) steam turbine rotors after prolonged service exposure ${ }^{[1]-[4]}$. The results revealed that the degree of performance degradation is related to service temperature, service duration and stress level, among which the influence of service temperature and service duration played roles more significant. Investigations by Joarder and Cheruvu showed that service exposure at $288^{\circ} \mathrm{C}$ for 23 years resulted in no changes in microstructure and mechanical properties in CrMoV steel ${ }^{[2,3]}$. Studies by Zhao showed that no decreasing occurred in tensile strength after 16year in-service at $300^{\circ} \mathrm{C}$ in $30 \mathrm{Cr} 2 \mathrm{Ni} 4 \mathrm{MoV}$ steel ${ }^{[5]}$. With the increase of service temperature between $350^{\circ} \mathrm{C}$ and $527^{\circ} \mathrm{C}$ after long-term service exposure, service embrittlement or softening behavior, coarsening and coalition of the precipitates occurred in $\mathrm{CrMoV}$ rotor steel ${ }^{[2,3]}$. However, all above investigations focused on forged rotors, little work has been conducted to characterize comprehensive performance evolution of welded joints after long-term service for the welded rotor.

In order to evaluate the influences of long-term service under severe working conditions such as high temperature and high pressure on the microstructure evolution and mechanical properties of welded joints of NiCrMoV steel, the LP welded rotor which had been in service for 22 years (close to 200,000 hours) was

Corresponding author: fanmj@ shanghai-electric.com 
studied. The material samples for this study were taken from the region in which the serving temperature was as high as $230^{\circ} \mathrm{C}$. Microstructure analysis, roomtemperature tensile tests and fracture toughness were carried out for the SAW welded joints to evaluate the reliability of welded rotors manufactured in similar ways.

\section{Experimental Procedure}

\subsection{Fabrication of the retired welded rotor}

The studied steam turbine LP welded rotor was manufactured in 1990s by Shanghai Turbine Plant, and retired in 2013 (as shown in Fig.1a). The welded rotor consisted of two shaft ends and five discs, and six welds with the maximum outer diameter $1295 \mathrm{~mm}$ were fabricated. Fig.1b shows the welded rotor after the impeller grooves were cut off by machining.

TIG with filler wire was used in the back beads, while multilayer SAW in the subsequent passes. Post weld heat treatment is head in $610-620^{\circ} \mathrm{C}$ for 36 hours. Table 1 is the chemical composition of $\mathrm{NiCrMoV}$ steel as the base metal.

\subsection{Microstructure characterization and}

\section{mechanical properties tests}

Specimens were sampled from the welded joint nearest to the middle of the welded rotors in axial direction, where the inlet temperature was the highest as much as $230{ }^{\circ} \mathrm{C}$ thus the severest microstructural degradation was expected.

Specimens for optical microscope observation were prepared by mechanically grinding and polishing, followed by picric acid etching in boiling water. Tensile strength tests specimens of weld metal and base metal were prepared by machining, and the geometry of tensile specimen is shown in Fig.2a. Compact tension (CT) specimens of weld metal, HAZ and base metal were also prepared for fracture toughness tests, in which the notch located at weld metal, HAZ and base metal, respectively. The geometry of CT specimen is shown in Fig. $2 \mathrm{~b}$.

\section{Results and Discussion}

\subsection{Microstructure and hardness of SAW weld metal after service exposure at $230^{\circ} \mathrm{C}$ for 22 years}

In this investigation, specimens sampled from welded joint including base metal, HAZ and weld metal were used for conventional optical metallography study. Fig.3a shows the macrostructure of welded joint, and the width of the HAZ is estimated to be about $4 \mathrm{~mm}$. Magnified images of base metal, HAZ, and weld metal are presented in Fig. 3b, 3c and 3d, respectively.

The microstructure of base metal is characterized by equiaxed grains, of which the size ranges from 30 to 200 $\mu \mathrm{m}$, as shown in Fig. 3b. Fig. 3d reveals that the microstructure of weld metal is featured by columnar grains. No obvious defects such as creep cavities, cracks were observed, neither grain coarsening.

Table 1. Chemical composition of NiCrMoV steel ( wt \% )

\begin{tabular}{|c|c|c|c|c|c|}
\hline $\mathrm{C}$ & $\mathrm{Si}$ & $\mathrm{Mn}$ & $\mathrm{Mo}$ & $\mathrm{Cr}$ & $\mathrm{Ni}$ \\
\hline 0.22 & 0.11 & 0.78 & 0.83 & 1.90 & 1.05 \\
\hline $\mathrm{V}$ & $\mathrm{P}$ & $\mathrm{S}$ & $\mathrm{Cu}$ & $\mathrm{Fe}$ & $/$ \\
\hline 0.07 & 0.002 & 0.003 & 0.04 & Balanced & $/$ \\
\hline
\end{tabular}
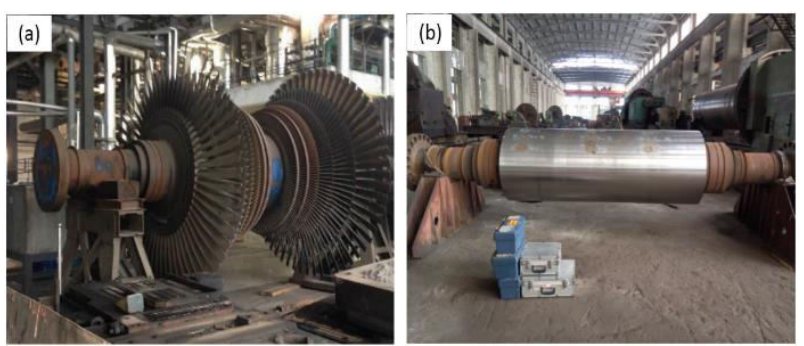

Fig.1. Retired welded rotor. (a) with turbine blades and (b) after machining the outer circle.
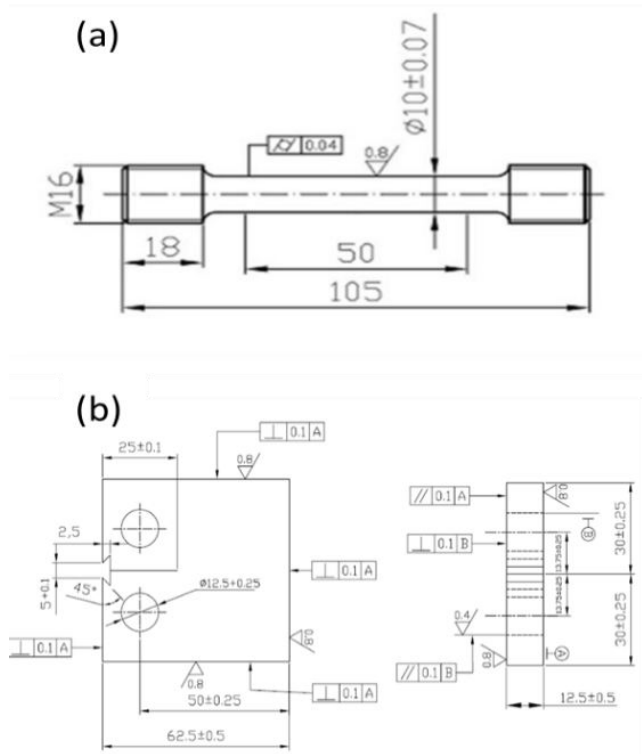

Fig. 2. Specimen for(a) tensile strength tests and (b) fracture toughness tests

The micro-hardness across welded joint was measured, of which the base metal is between HV210 and HV230, and weld metal is between HV200 and HV220. In the HAZ, the micro-hardness of the overheated coarse-grained zone is the highest, about between HV280 and HV290. The hardness distribution across the welded joint shows no obvious abnormity. In addition, it was noted that some black strip-shaped zones were found in the HAZ and base metal, and the color of the black strip in the HAZ is darker, as shown in Fig. 3a. 
In HAZ near the fusion boundary, some light-colored zones were observed between the black strips, which were speculated to be ferrite microstructure with low easy to be etched by picric acid and the prior austenite grain boundaries could be easily identified, which might be attributed to the large amount of carbides precipitated in the zones.

In order to find the reasons for the formation of black strips, the micro-hardness of the black and light-colored zones in HAZ near fusion boundary was tested, as shown in Table 2. The average micro-hardness of black strips is about $10 \%$ higher than that of light-colored zones, which indicates that the black strips probably resulted from carbon segregation.Based on the assumption that the black strips had already existed before service and black strips resulted from carbon segregation, the relationship between the revolution behavior of black strips and welding thermal cycles can be further discussed. If the carbon content, as shown in Fig. 3c. Besides, it was found that the black strips were

segregation of carbon in black strips had already existed in the forgings, the $\mathrm{Ac}_{1}$ temperature of the black strips would be lowered by carbon segregation. During welding, the region with high carbon content would transform into austenite from ferrite prior to the adjacent light-colored zone (carbon depleted zone), meanwhile, carbon atoms in the light-colored zone would diffuse into the adjacent austenite zone due to its higher carbon solution. That is why segregation of carbon in HAZ is much more severe than that in base metal. Although carbon segregation occurred in base metal and HAZ, no microstructural discontinuity such as cavities and cracks were observed, which indicates that it might have no detrimental effects on the welded joints.

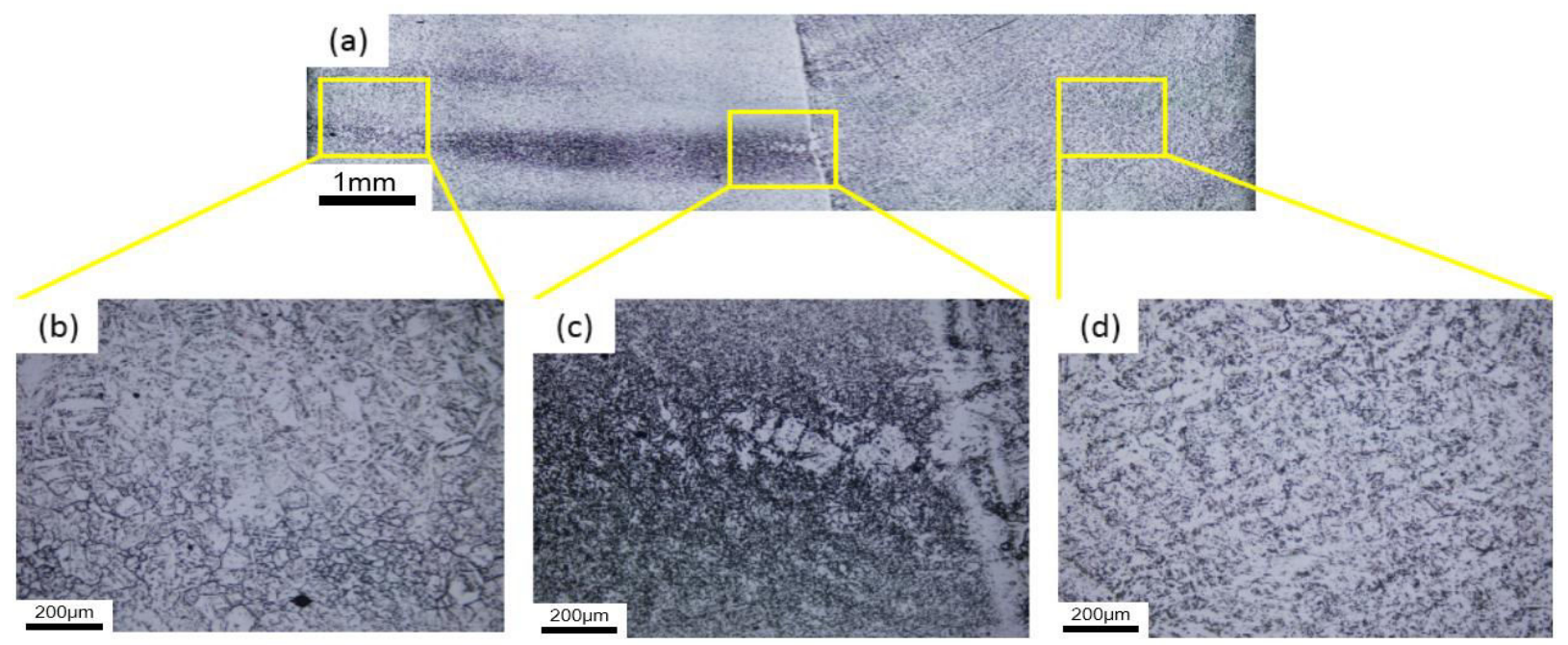

Fig.3. Optical images of $\mathrm{NiCrMoV}$ steel welded joint of the retired welded rotor. (a) macrostructure of welded joint, (b)microstructure of base metal,(c)microstructure of HAZ, and(d) microstructure of weld metal

Table 2. Micro-hardness of the black and non-black bands (HV)

\begin{tabular}{|c|c|c|c|c|c|}
\hline Measured position & 1 & 2 & 3 & 4 & average \\
\hline black strips & 237 & 246 & 243 & 237 & 241 \\
\hline light-colored zone & 216 & 223 & 228 & 223 & 223 \\
\hline
\end{tabular}

\subsection{Tensile properties at room temperature}

The room-temperature tensile properties of base and weld metal were tested, and compared with the data of base metal obtained before service. The values of ultimate tensile strength, yield strength, elongation, and reduction in area were determined, as listed in table 3.

According to the data in Table 3, it is clear that the tensile properties of base metal remain unchanged after long term service. The average values of ultimate tensile strength, yield strength, elongation, and reduction in area of weld metal after service are $657 \mathrm{MPa}$ and $543 \mathrm{MPa}$, $19.7 \%$, 68\%, respectively. It obviously shows that the tensile strength and yield strength of weld metal only reduce approximately $11 \%$ than that of base metal. In general, the strength of weld metal of NiCrMoV steel is close to $90 \%$ of that of base metal after PWHT. It can be inferred that the welded joint of $\mathrm{NiCrMoV}$ steel have good performance in service.

Table 3. Comparison of tensile properties of $\mathrm{NiCrMoV}$ steel weldment before and after service

\begin{tabular}{|c|c|c|c|c|}
\hline & $\mathrm{R}_{\mathrm{m}} / \mathrm{MPa}$ & $\mathrm{R}_{\mathrm{p} 0.2} / \mathrm{MPa}$ & $\mathrm{A} / \%$ & $\mathrm{Z} / \%$ \\
\hline $\begin{array}{c}\text { base metal } \\
\text { (before service) }\end{array}$ & 736 & 616 & 27.4 & 77 \\
\hline $\begin{array}{c}\text { base metal } \\
\text { (after service) }\end{array}$ & 734 & 611 & 23.5 & 73 \\
\hline $\begin{array}{c}\text { weld metal } \\
\text { (after service) }\end{array}$ & 657 & 543 & 19.7 & 68 \\
\hline
\end{tabular}

\subsection{Fracture toughness behavior}

Multi specimen method was applied for J-integral resistant curve determination to measure the value of $\mathrm{J}_{\mathrm{IC}}$. In the multiple specimen method, a set of CT specimens 
were loaded to different displacements to make various crack extensions, then unloaded and fractured by fatigue load. Before fracture toughness testing, the CT specimens were fatigue-precracked at room temperature to ensure that a sharp crack was prepared in front of the machined notch. The initial crack length and stable crack growth can be determined by optical measurements for each specimen. Then a series of data points of $J_{R}-\Delta a$ can be plotted.

Basically, according to ASTM E813-87 and 89, the $\mathrm{J}_{\mathrm{R}}-\Delta \mathrm{a}$ data points between two exclusion lines parallel to the blunting line at crack extension $\Delta \mathrm{a}=0.15 \mathrm{~mm}$ and $\Delta \mathrm{a}=1.5 \mathrm{~mm}$ are used to fit the $\mathrm{J}_{\mathrm{R}}$ curve with which the intersection of a $0.20 \mathrm{~mm}$ offset line indicates the crack resistance $\mathrm{J}_{\mathrm{Ic}}$. Note that the value of $\Delta \mathrm{a}$ is the crack extension beyond the precrack. For each test, at least 6 valid data were required to plot the $J_{R}$ curve.

The $J_{R}$ curves of base metal, weld metal and HAZ were plotted in Fig. 4a, b and c, respectively, and the power law regression was employed to fit the $J_{R}$ curves and $J_{\text {Ic }}$ were obtained by the intersection with a $0.20 \mathrm{~mm}$ offset line.

The $\mathrm{J}_{\mathrm{IC}}$ value of the base metal, weld metal, HAZ is $362 \mathrm{KJ} / \mathrm{m}^{2}, 203 \mathrm{KJ} / \mathrm{m}^{2}, 397 \mathrm{KJ} / \mathrm{m}^{2}$, respectively. The values of $\mathrm{K}_{\mathrm{Ic}}$ can also be calculated according to the following equation:

$$
\mathrm{K}_{I C}^{2}=J \cdot \frac{E}{1-v^{2}}
$$

Where E is Young's modulus (Generally, $206 \mathrm{MPa}$ for steels) and $v$ is Poisson's ratio ( 0.3 for steels).

Correspondingly, the $\mathrm{K}_{\mathrm{Ic}}$ values of the base metal, weld metal and $\mathrm{HAZ}$ are $286 \mathrm{MPa} \cdot \sqrt{m}, 214 \mathrm{MPa} \cdot \sqrt{m}$ and300 $\mathrm{MPa} \cdot \sqrt{m}$, respectively. The results show that the $\mathrm{K}_{\mathrm{Ic}}$ of the weld is slightly lower those of base metal and HAZ.

Due to the lack of fracture toughness data before service, it is impossible to know the changes of fracture toughness after service. Here, some fracture toughness data of similar base metals from published literatures [6]-[8] are cited to be compared with the retired rotors, as listed in Table 4.The materials in Ref. [6] and [7] are $30 \mathrm{Cr} 2 \mathrm{Ni} 4 \mathrm{MoV}$ steel, and $25 \mathrm{Cr} 2 \mathrm{Ni} 2 \mathrm{MoV}$ steel in Ref.[8]. Table 4 indicates that the fracture toughness of various regions including base metal, weld and HAZ after longterm service is comparable to that of $30 \mathrm{Cr} 2 \mathrm{Ni} 4 \mathrm{MoV}$ or $25 \mathrm{Cr} 2 \mathrm{Ni} 2 \mathrm{MoV}$ base metal before service. The comparison indicates that the fracture toughness of welded joints remains at a high level after service for 22 years.

(a)

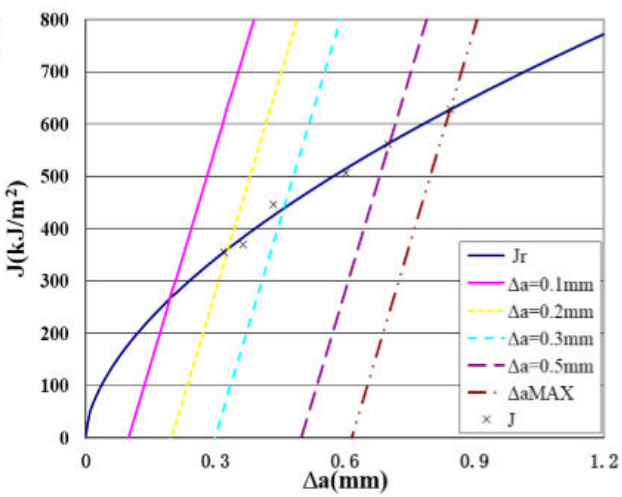

(b)

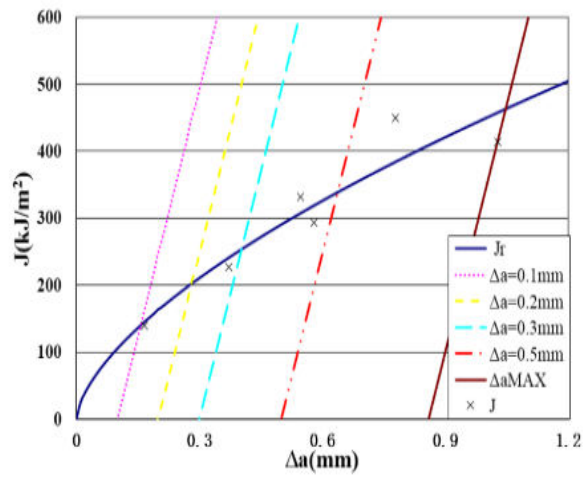

(c)

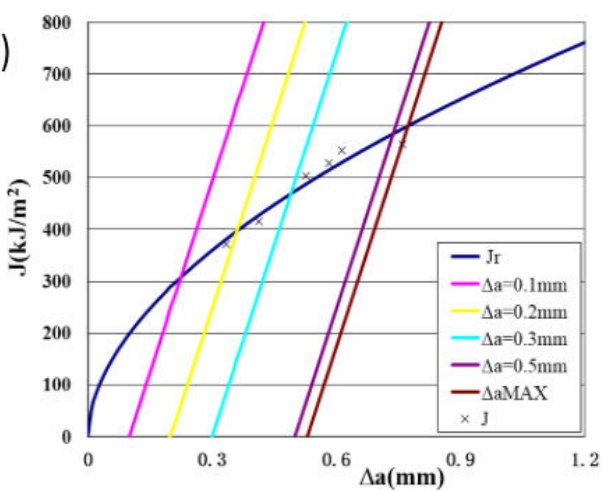

Fig.4. $\mathrm{J}_{\mathrm{R}}$ curves. (a) base metal,(b)weld metal and (c)HAZ

Table 4. Comparison of fracture toughness (KIC) between the present test results and published results in other literatures

\begin{tabular}{|c|c|c|c|c|c|}
\hline \multicolumn{3}{|c|}{$\begin{array}{l}\text { test results } \\
\text { (after service) }\end{array}$} & \multicolumn{3}{|c|}{$\begin{array}{l}\text { literature results } \\
\text { (before service) }\end{array}$} \\
\hline $\begin{array}{l}\text { base } \\
\text { metal }\end{array}$ & $\begin{array}{l}\text { weld } \\
\text { metal }\end{array}$ & HAZ & $30 \mathrm{Cr} 2 \mathrm{Ni} 4 \mathrm{MoV}^{[6]}$ & $30 \mathrm{Cr} 2 \mathrm{Ni} 4 \mathrm{MoV}^{[7]}$ & $25 \mathrm{Cr} 2 \mathrm{Ni} 2 \mathrm{MoV}^{[8]}$ \\
\hline 286 & 214 & 300 & 164 & 220 & 230 \\
\hline
\end{tabular}

\section{Conclusions}

The effects of long-term service on the microstructure and mechanical properties of NiCrMoV LP welded rotor steel were investigated in the present study. The conclusions drawn are as follows.

1. Service exposure at $230^{\circ} \mathrm{C}$ for 22 years results in no deterioration in microstructure, and no obvious grain coarsening were found throughout the welded joint. Black strip shaped zones were found in HAZ and base metal, and it is considered that the black strips existed before service.

2. The micro-hardness distribution of the welded joint showed no obvious abnormity. The hardness level of HAZ was found to be generally greater than that of base metal and weld metal.

3. The tensile properties of base metal after service is comparable to that before service, and basically no change could be identified. The tensile strength, yield strength, elongation and reduction of area of weld metal after service are $657 \mathrm{MPa}$ and $543 \mathrm{MPa}$, $19.7 \%$ and $68 \%$, respectively. The strength and 
plasticity of the welded joint of the retired rotor Remained at a high level.

4. The comparison of fracture toughness between the welded joint of the retired rotor and published data by other researchers before service indicates that the fracture toughness of welded joints is still at a high level even after service for 22 years.

5. With the improvement of forging and welding qualities and improved heat treatment furnaces with more accurately controlled temperature, it is reasonable to assume that the current large lowpressure (LP) welded rotors are definitely safe to operate under similar service conditions for designed life.

\section{References}

1. N.S. Cheruvu.Metall. Mater.Trans.A.20,1(1989)

2. N.S. Cheruvu, B(b). Seth. Metall. Mater.Trans.A. 20,11(1989)

3. A. Joarder, D.S. Sarma ,N.S. Cheruvu, Metall. Mater.Trans.A. 22,8(1991)

4. P. K. Liaw, M. G. Burke, A. Saxena. Metall.Mater.

Trans.A. 22,1(1991)

5. YM Yan, ZF Hu, FS Lin, and SQ Zhao.T Mater Heat Treat. 34,1(2013)

6. ZW Yue, YN Zhao, JE Zhou. Electric Power. 30,12(1997)

7. RF Li, Y Zhang, J Chen, MY Wang. Power System Engineering. 19 , 4 (2003)

8. HW Shen, SY Wang, X Liu. Thermal Turbine. 37,3 (2008) 